Beccari, Enrico.

Profesor asociado de la Universidad de Barcelona - departamento de Artes Visuales y Diseño (Pedagogías Culturales)

\title{
Relatos (secuenciales) en la red-el cómic autobiográfico y los nuevos contextos de producción y difusión.
}

\section{(Sequential) tales over the net - autobiographical comics and new context of production and distribution.}

\author{
TIPO DE TRABAJO: \\ Comunicación. \\ PALABRAS CLAVE: \\ Cómic; autobiografía; mercado; tecnología; Internet. \\ KEY WORDS: \\ Comic; autobiography; market; technology; Internet.
}

\section{RESUMEN.}

Como efecto de la globalización y de las nuevas tecnologías de comunicación y difusión de contenidos, aumenta el abanico de narrativas gráficas que aprovechan cambios concretos en las modalidades de distribución y comercio para elaborar distintas estrategias de autopublicación, llevadas a cabo a través de plataformas de distribución global, convertidas en mediadores privilegiados.

Entre las distintas formas de narrativas autobiográficas, el cómic se diferencia por la necesidad de organizar una narrativa tanto visual como textual. Sin embargo, en la contemporaneidad, la delicada tarea del relatarse en viñetas incluye insertarse en un contexto más amplio, donde el producto final pasa, ahora, por filtros diferentes a los de antaño. Así, acaban difundiéndose globalmente narrativas personales, en un contacto constante (pero no necesariamente dialéctico) con el otro - otras culturas, o la cultura de uno/a mismo/a, representadas en el cómic con el pretexto implícito del pacto autobiográfico.

Propongo, entonces, un primer análisis de cómo el paso a un mercado global (y digital) ha producido cambios y generado nuevas dinámicas en esta práctica artística. La intención, de cara a futuras investigaciones, es esbozar un primer estado de la cuestión, definir condiciones, actores sociales y evidenciar relaciones de poder - como, por ejemplo, cuáles voces emergen, qué diferencias existen en términos de género, nacionalidad, origen geográfica - tratando de entender cuáles modalidades de relato ganan espacios, y cuáles permanecen invisibles.

Tomando en consideración los cambios emergidos, aproximadamente, en la última década, me orientaré principalmente hacia el contexto de producción/difusión de la novela gráfica norteamericana, por ser el donde se originan las recientes tendencias autobiográficas, el ámbito de mi investigación doctoral y porque, entre otros, la producción en idioma inglés es un factor de impacto más, que desde lo "local" (Estados Unidos y Canadá) acaba por resonar a nivel global, generando ulteriores posibilidades de estudio.

\section{ABSTRACT.}

As an effect of the globalization and the introduction of new technologies for commercial communication and content diffusion, it can be noticed an increment in the number of graphic narratives that take advantage of specific changes in 
distribution and trade dynamics, in order to elaborate different types of self publishing strategies, performed through global distribution platforms, now becoming privileged mediators.

Among the many forms of autobiographic narratives, comics stands out because of the need for organizing a both textual and graphic narrative. Yet, in the present historical moment, the delicate task of narrating oneself through sequential panels implies entering in a broader context, where the final product passes now through different filters than those functioning before. Thus, personal narratives end up spreading globally, in a constant (but not necessarily dialogic) contact with the other - other cultures, or even one's own, represented in the comic under the implicit pretext of the autobiographical pact.

I propose, therefore, a tentative analysis of how the passage to a global (and digital) market has generated changes and new dynamics in this particular artistic practice. Looking forward to further research, here I intend to delineate the context, defining conditions, involved social actors, as well as highlighting power relationships - emerging voices, differences regarding sex, nationality, and geographical origin - in an attempt to understand which modes of narration are gaining new spaces, and which ones remain invisible.

Taking into account changes ocurred during, aproximately, the last decade, I will orientate myhe analysis mainly toward the North American context of production and diffusion, being this at the origin of the recent autobiographical trend, the focus of my PhD research, and also because english language production is an important factor from where the "local" (United States and Canada) ends up resonating on a global level, generating opportunities for further studies.

\section{CONTENIDO.}

\section{El cómic autobiográfico en los tiempos de la pantalla digital.}

A lo largo de mi investigación doctoral acerca de la construcción de la identidad en la novela gráfica autobiográfica de última generación, he tenido la posibilidad de recorrer la trayectoria histórica de este género específico de la narrativa secuencial, siguiendo su evolución desde las primeras, aisladas publicaciones independientes hasta el resurgir de la autobiografía gráfica como una tendencia relativamente influyente en el mundo de los cómics alternativos de los años 90. Dicho trend autobiográfico nace, principalmente, en el ámbito angloamericano, para luego llegar, junto con la evolución general de la novela gráfica, a la internacionalización y expansión en Europa con el nuevo milenio, donde se consolida su estatus como género literario autónomo y bastante prominente dentro del consumo cultural del cómic (García 2010, pp. 215-222 y 234-264; y Baetens \& Frey 2015).

A nivel aunque sea de simple observación cotidiana, resulta claro que la actual proliferación de múltiples formas de relatar la experiencia de vida, desde los reality show a las nuevas prácticas comunicativas en las que se intercambian imágenes y filmados (Facebook, Instagram, Pinterest), pasa cada vez más por representaciones gráficas. En este sentido, parece confirmarse la intuición de Mirzoeff $(1999$, p.1), según quien la vida moderna se desarrolla en la pantalla. Pero, si consideramos las prácticas ante citadas, diremos también que la vida moderna se construye en la pantalla y, finalmente, se difunde en la pantalla. ¿Qué lugar ocupa el cómic autobiográfico en este panorama en constante y rápida evolución?

Paralelamente a la globalización y la entrada en nuestras vidas de nuevas tecnologías de comunicación y difusión de contenidos, aumenta el abanico de narrativas secuenciales que relatan aspectos de la vida de los autores de forma gráfica - y que Whitlock, 2006, define de forma específica como autographics. En su proliferación, estas narrativas cabalgan los cambios continuos en los modos de creación y distribución, para fomentar su difusión a nivel, potencialmente, mundial. Aprovechan, además, distintas estrategias de autopublicación por parte de autores, tanto profesionales como amateur. Estas incluyen el micromecenazgo (crowdfunding), la publicación autónoma en sitios web privados o en redes sociales en plataformas de comercio y distribución global. ${ }^{1}$

Partiendo de esta premisa, quisiera esbozar un primer análisis de los procesos y de los actores principales del cómic autobiográfico en su circulación global, individuando las entidades y modalidades de difusión más prominentes; a la vez, a través de unos casos representativos, argumentaré como los procesos de globalización (en términos económicos, vinculados con el mercado y con las distintas modalidades de difusión) han permitido, en este sector específico, la difusión de nuevos relatos, nuevas voces, y modalidades de relatar - a la vez que se generan dinámicas discutibles, sombras y posibles exclusiones. Mi intención es abrir frentes de investigación acerca de la novela gráfica autobiográfica en la época de la publicación digital y globalizada, señalizando, así, temáticas de interés para futuras pesquisas en el campo de los estudios del cómic.

\footnotetext{
${ }^{1}$ Hay importantes aspectos relacionados con los cambios tecnológicos y el mercado del arte como, justamente, el micromecenazgo; sin olvidar los efectos del giro hacia el dibujo digital sobre la misma práctica artística. Por razones de espacio, sin embargo, no podré abordarlos en este escrito.
} 


\section{La difusión másiva, global y en digital: el caso de Amazon.}

Janet Wolff , en su conocido texto de sociología del arte, sugiere de considerar una serie de factores concretos, además del análisis ideológico, para analizar la producción social del arte (Wolff 1997, pp. 47-63). Entre estos factores - entrelazados entre ellos - cabe incluir el papel de las instituciones, del mercado, y de la tecnología. En este escrito, centrándome sobre todo en las últimas dos, subrayaré también el papel institucional y dominante de Amazon, entendido como ejemplo de mediador privilegiado en el comercio de los libros digitales.

Para empezar, es importante considerar las novelas gráficas no sólo por su contenido, sino también como producto en venta - es decir, libros. A grandes rasgos, como en cualquier producción literaria, se pueden evidenciar tres tipos de actores sociales implicados: el productor (artista y escritor); los mediadores, representados ahora por los gigantes de la distribución mundial de textos en distintos formatos (físicos y no); y finalmente el comprador/consumidor - que, hoy en día, se encuentra en una posición diferente con respecto a su interacción y acceso al producto.

En cuanto al mercado, el cambio tecnológico en los dispositivos de lectura, que propone tablet, eReaders y móviles como alternativa flexible y barata a los libros tradicionales, posibilita el disfrute de productos que tienen un precio sensiblemente más bajo que en su contraparte de papel. El proceso de compra de un libro digital resulta fácil y rapidísimo, con posibilidad de acceso desde todos los dispositivos del usuario. Esto - en línea con la necesidad constante del neo capitalismo de rellenar espacios y reducir los tiempos de entrega de un producto al propietario, para que este siga comprando - anula la espera y borra la necesidad de toda una serie de intermediarios que antes eran parte necesaria de la cadena para acceder al producto (mayoristas, transportistas, empleados de una tienda de libros...). Luego, el proceso de lectura dirige el lector a disfrutar el libro comprado principalmente o exclusivamente a través del acceso del programa vinculado a su cuenta de usuario - por lo tanto, el file del libro en sí, resulta relativamente difícil de duplicar y, al contrario de un libro real, no se puede prestar a nadie. En efecto, le parece a uno tener un libro o una novela gráfica en una especie de "préstamo permanente", lo cual alimenta - aunque esto es sin duda subjetivo - una cierta sensación de vigilancia.

Por lo que concierne la publicación de libros digitales, se puede poner el 2007, fecha en la que Amazon lanza su lector de libros Kindle (Levy 2007) como fecha clave para la difusión de contenido autopublicado, y de los libros digitales (Wasserman 2012). Un par de años después, ofrecerá a los usuarios la posibilidad de publicar y vender, aprovechando el formato digital, sus propios libros (y cómics).

Está claro que este nuevo orden implica cambios de papeles en figuras antaño relevantes. Las editoriales tradicionales, aunque obviamente no han desaparecido, se notan en evidente dificultad frente a estas nuevas dinámicas de producción, distribución y consumo. Por lo tanto, la expansión de Amazon en el campo de la cultura escrita no ha sido sin conflictos, como demuestra el conflicto con la editorial Hachette (Monge 2014) sobre cuestiones económicas relativas al margen de beneficio. Esta expansión ha evidentemente preocupado personalidades del mundo y del mercado de la cultura - como demostrado por la simbólica acción de protesta emprendida por unos escritores al denunciar como un monopolio las prácticas comerciales de Amazon (Vauhini 2015), un debate al que pronto se juntaron más voces (Norton 2016).

\section{El cómic líquido y sus creadores.}

En estos últimos años, el mercado de Amazon Publishing se ha ampliado, incluyendo no sólo obras de ficción comercial, sino también ensayos, biografías y memoirs (Milliot \& Deahl, 2016). Datos de mercado parecen confirmar que, más o menos, el mercado para libros digitales está en crecimiento (Altares 2015); por otro lado, la situación para los cómics parece ser menos clara, y si miramos los números veremos que las ventas no favorecen de forma clara el mercado digital (DiChristopher 2016).

Estos datos no muy claros invitan a ulteriores reflexiones. Por un lado, parece existir una fascinación por la novela gráfica física, tangible, espesa; y se nota como esta se preste bien para fomentar una cultura de la novela gráfica como un objeto dotado de singularidad. Pero cabe añadir otro detalle: por lo que concierne el cómic, la impresión es que Amazon no favorezca el mercado de los comic books, apostando en cambio por las novelas gráficas - que disponen de opción de envío global del libro en papel, además de la posibilidad de adquirir la edición digital, si esta existe. Al mismo tiempo, la lenta pero segura difusión del cómic en formato digital, indica de que el público se está acostumbrando a leer cómics en la pantalla.

La conclusión es que el sumarse de estas coyunturas favorezcan la difusión de nuevas narrativas (la novela gráfica, el relato largo pero autoconclusivo), a la vez que se limitan otras (las narrativas cortas y/o seriales). Por lo tanto, se trata de ver en qué otros lugares pueden emerger las narrativas autobiográficas que no responden al modelo del libro, de por sí todavía céntrico si miramos la gran distribución.

En este sentido, la nueva oleada de narrativas gráficas autobiográficas aprovecha no sólo las posibilidades ofrecidas por los grandes mediadores, sino las sinergias que se generan con la interacción directa con los usuarios en la red, a través de sitios web personales y redes sociales de vario tipo. Obviamente, hablar de webcomics significa entrar en un mundo bastante difícil de mapear, donde serios intentos por llegar al profesionalismo se mezclan con expresiones de creatividad ambiciosa pero dispersa, sitios web que se paralizan o desaparecen de un día para otro, etcétera. Creo, sin embargo, que puede ser interesante proponer algunos ejemplos, 
para ilustrar como el prescindir (parcialmente o totalmente) da la editorial como mediador genere perfiles de artistas distintos de los de antaño: el dibujante de novelas gráficas contemporáneo parece ser un artista multifacético, activo en distintas plataformas, autónomo y experto en DIY, marketing y autopromoción.

Quizás un caso emblemático sea el de James Kochalka, que en el 2007 aprovechaba su sitio web para compartir gratuitamente los contenidos de su tira autobiográfica (American Elf), que llevaba dibujando ( $y$, sucesivamente, publicando en línea en el sitio americanelf.com) diariamente desde el 1998. Compartir en línea viñetas nuevas y antiguas ha repercutido positivamente en la popularidad del cómic, con excelentes éxitos de difusión (Alverson, 2012). Al mismo tiempo, Kochalka nunca ha cortado definitivamente la relación con las editoriales tradicionales: al parecer, ha desactivado su sitio web personal (que ahora dirige al perfil comercial de Kochalka en la editorial Top Shelf, con la que el autor colabora). Sea como sea, estos cambios demuestran como la flexibilidad para gestionar la relación dinámica con el público, sus constantes demandas e imprevisibles reacciones se haya convertido en una habilidad imprescindible para el autor de cómics "global".

En lo específico del cómic autobiográfico, el de Kochalka es, sin duda, una nueva voz: sus narrativas fragmentadas capturan viñetas de vida cotidiana, microhistorias que poco tienen de político o incluso de sátira. Es posible trazar una historia de la vida de Kochalka a partir de una lectura global da las viñetas, pero está claro que un ritmo de publicación cotidiano necesita de un diálogo con el público intenso y posible solo con una serialización instantánea en línea - que refleja, de una forma que sólo el cómic puede, la atomización de imágenes y fragmentos de vida. Como comenta el mismo Kochalka (entrevistado por Verstappen, 2008), el empeño de presentar una nueva viñeta todos los días se convierte en un elemento estructurante de la vida del artista, a la vez que es un continuo ejercicio de reflexividad. Se nota aquí una tensión entre la nuevas entregas cotidianas y la posibilidad, ofrecida libremente, de consultar el archivo: la lectura en línea se ralentiza, se fragmenta, devuelve la sensación de construcción desordenada pero continua, de los recuerdos y episodios de la vida de Kochalka - y, por extensión nos recuerda la nuestra.

\section{Nuevas voces desde lo femenino y lo queer.}

Como se ha comentado hasta ahora, los cambios en el contexto relacional en el que el cómic autobiográfico se produce y se difunde han generado dinámicas diferentes, con algunas sombras vinculadas a los discursos del mercado, pero a la vez haciendo posible que voces desde el cómic más marginal sean oídas - recupero aquí el concepto de voz, en términos propuestos por Britzman (1989) y Mazzei y Jackson (2009). Este se refiere al derecho de cada uno, o de un grupo social, representarse y ser representado, de hablar, precisamente, de sus propias experiencias, presentando sus reflexiones ante otros; y manteniendo cierto control acerca de su propia representación.

Entonces, ¿cuáles voces emergen en los cómics autobiográficos publicados en la red? A nivel general, se puede decir que el relato autobiográfico rescata voces femeninas y queer de forma bastante más evidente que en otros géneros narrativos. En parte, la impresión es que en esto influya el papel de otras voces, esta vez críticas y académicas: las narrativas autobiográficas, gracias en buena parte a la (auto)publicación digital, han permitido no sólo la difusión de graphic novels autobiográficas, sino también de textos críticos acerca de las mismas (por ejemplo, Chute 2010) que antes no hubiesen sido tan fácilmente al alcance. Esta difusión de conocimiento crítico, que luego desborda en blogs, sitios con material pirateado, etc, alimenta sin dudas el conocimiento teórico de las nuevas autoras (que por lo general tienen formación académica) y fomenta la consciencia de ser parte de un grupo social que exige una correcta representación mediática.

Pero hay cambios incluso dentro de estas corrientes. Con respecto a anteriores olas del cómic autobiográfico, la sensación es que los nuevos cómic autobiográficos se alejen, en parte, de ambiciones marcadamente políticas, para explorar microhistorias ambientadas en la cotidianidad. Es decir, que emergen voces irónicas y casi normativas, y no sólo herederas directas de cierta actitud contracultural que caracterizaba, por ejemplo, el cómic alternativo femenino (y feminista) de los años 90.

Por lo que concierne las voces queer, precisamente, si Alison Bechdel ha sido desde el principio elegida (seguramente desde la crítica académica, que le ha dedicado mucha atención) como representante principal del autobiografismo queer, es cierto que el mundo de los comics en línea ofrece otras voces representativas de un desarrollo artístico que corre paralelo a los cambios de los medios de comunicación. También cabe considerar cuestiones generacionales, ya que Bechdel escribe su primera autobiografía en viñetas, Fun Home, en el 2006, cuando ya tiene una trayectoria de más de 20 años como cartoonist. Por ello, su relación con las dinámicas de la red es seguramente distinta de la que puedan tener dibujantes más jóvenes, aún presentando cierta similaridad en los temas tratados.

Es el caso de Erika Moen, joven artista que ocupa diferentes lugares en línea, para diferentes subjetividades, expresadas a través de relatos y fragmentos autobiográficos: al lado del sitio web con su nombre real, extiende su presencia en darcomic.com, donde por seis años ha dibujado su transito identario, como lesbiana que acaba, inesperadamente, por enamorarse de un hombre, eligiendo al final la definición de sí misma como queer para, justamente, no-definirse. Luego, en ohjoysextoy.com, Moen relata de forma descaradamente directa y gráfica su pasión y experiencias con los juguetes sexuales, mezclando autopromoción, consciencia política sobre el género y experimentación visual: sus tiras se desarrollan a menudo en un sentido vertical, como un pergamino, adaptándose a las características de una pantalla vídeo, o de un tablet o móvil. 


\section{Viñetas globales y subjetividades (occidentales) en viaje.}

Extendiendo el término autobiográfico más allá de los memoirs o de las narrativas fragmentadas centradas en el autobiografismo de la cotidianidad, encontraremos otras voces y otros tipos de narración, siempre representadas en el cómic con el pretexto de algún tipo de pacto autobiográfico (LeJeune, 1994), concepto que, a pesar de la necesaria revisión a la que ha sido sometido por el pensamiento posmoderno, sigue siendo de utilidad estratégica para explicar la atractiva de las narrativas autobiográfica.

Los travelogues o narrativas de viaje son, entonces, otro tipo de narrativa autobiográfica que tiene bastante representatividad y que ha surgido con el nuevo milenio, marcando un cambio visible en el mundo del cómic. Un ejemplo clave sería el noto Pyongyang (2005), relato gráfico del dibujante canadiense Guy Delisle, en el que cuenta su singular experiencia como profesional de la animación en la Corea del Norte, y las impresiones maduradas acerca de la vida cotidiana en un régimen totalitario y casi panóptico en su forma de vigilar tanto a la población como a los visitantes. En la época de publicación de la novela gráfica, se prohibía estrictamente la circulación de imágenes fotográficas fuera del país asiático, pero Delisle logra hacer pasar sus viñetas sobre Corea del Norte completamente desapercibidas. Es entonces interesante notar que, al no tener la capacidad de interpretar los códigos del cómic, los controles de aduana nordcoreanos fallan a la hora de descifrar la potente capacidad descriptiva y de crítica política que, tal y como las fotografías, el arte secuencial puede ejercer. Aquí, el pacto autobiográfico, paradójicamente, encuentra refuerzo justamente en el dibujo, aunque este renuncie de entrada a cualquier pretensión de realismo documental.

No hay, de todas formas, que interpretar le relato de Delisle como un relato declaradamente político - es más una mirada de asombro hacia un mundo global al que el autor, en el fondo, no pertenece, quedando muy arraigado en su identidad y posición de occidental y canadiense. Por otro lado, el éxito de esta novela gráfica abre camino para otros relatos como pueden ser los de Sarah Glidden (2011), que viaja a Israel para descubrir su propia identidad como judía americana; o como es el caso de Lucy Knisley (2008), que describe con curiosidad y entusiasmo su descubrimiento de la cultura francesa en su viaje a París - y, a la vez, explora su relación con su madre, que le acompaña. Así, en estos relatos (personales, o incluso íntimos) vemos las historias de subjetividades norteamericanas, occidentales, que cuentan experiencias de descubrimiento de un mundo otro, de otras culturas, a veces topándose con la otredad en la cultura de uno mismo. El viaje se convierte, una vez más, en un ejercicio gráfico de reflexividad y posicionamiento identitario.

Posicionamiento que, por otro lado, se puede leer de forma crítica, y no sólo en los aspectos que dependen directamente de los autores. Es decir, las voces que se difunden y que venden son, principalmente, las de autores nortemericanos, que escriben principalmente en idioma inglés, lo cual refuerza, implícitamente, la centralidad cultural del América del norte. El tema del idioma, y de como Amazon, entre todos, ha contestado a esta problemática es ramificado y complejo. Pero la impresión, aquí, es que en el caso de no colaborar con una estructura editorial tradicional, difícilmente los autores no consolidados tomarían iniciativa para emprender los pasos necesario para traducir y difundir los libros en otros idiomas que no sean el inglés.

\section{Conclusiones y mapas futuros.}

Con la intención de devolver un cuadro general de un panorama en constante movimiento, he tratado de evidenciar unos factores (tecnología y mercado por encima de todos) que permiten el proliferar de narrativas autobiográficas - una tipología de narrativa que, aunque no es la única ni la hegemónica, parece ser particularmente en sintonía con el zeitgeist actual. Inevitablemente, las mismas fuerzas acaban configurando mecanismos de regulación.

Pero, a través de algunos ejemplos escogidos a partir de una comparativa estratégica entre autores muy recientes y otros que se hacen notar al principio del nuevo milenio (cuando se afirma la retórica terminológica de la novela gráfica) he intentado también argumentar que los nuevos autores aprenden rápidamente a moverse en este contexto, multiplicando identidades y estrategias para resistir en un mercado fluido y mucho más relacional y complejo que el de antaño.

Queda pendiente un intento más extenso y completo de mapear esta red relacional, y definir las trayectorias presentes y futuras de la novela gráfica autobiográfica (y no).

\section{FUENTES REFERENCIALES.}

Altares, G. 2015. El libro de papel resiste la avalancha digital. En: El País. 3 Nov 2015.Disponible en: http://cultura.elpais.com/cultura/2015/10/23/actualidad/1445623004_054856.html

Alverson, B. 2012. Robot 6 Q\&A - James Kochalka On The End Of American Elf. En: cbr.com. 20 Dec 2012. Disponible en: http://www.cbr.com/robot-6-qa-james-kochalka-on-the-end-of-american-elf/

Baetens, J. \& Frey, H. 2015. The Graphic Novel: An Introduction. New York: Cambridge University Press. ISBN 978-1-107-65576-8 
Beccari, Enrico

Relatos (secuenciales) en la red - el cómic autobiográfico y los nuevos contextos de producción y difusión

III CONGRESO INTERNACIONAL DE INVESTIGACIÓN EN ARTES VISUALES :: ANIAV 2017 :: GLOCAL [codificar, mediar, transformar, vivir] http://dx.doi.org/10.4995/ANIAV.2017.4867

Bechdel, A. 2006. Fun Home: una familia tragicómica. Barcelona: Reservoir Gráfica. ISBN 978-8439721048

Britzman D. 1989. Who has the floor? Curriculum, teaching and the English student teacher's struggle for voice. Curriculum Inquiry, 19(2). Pp. 143-162. ISSN: 1467-873X

Chute, H. 2010. Graphic Women: life narrative and contemporary comics. New York: Columbia University Press. ISBN 978-0-231-521574.

Delisle, G. 2005. Pyongyang: A Journey in North Korea. Montréal, Québec: Drawn \& Quarterly. ISBN-13: 978-1897299210.

DiChristopher, T. 2016. Comic books buck trend as print and digital sales flourish. En: CNBC. 5 Jun 2016 . Disponible en: http://www.cnbc.com/2016/06/05/comic-books-buck-trend-as-print-and-digital-sales-flourish.html

Garciá, S. 2010. La novela gráfica. Bilbao: Astiberri. ISBN 978-84-92769-30-8.

Glidden, S. 2011. Una judía americana perdida en Israel. Barcelona: Norma editorial. ISBN 978-84-679-0478-9.

Knisley, L. 2008. French Milk. New York: Touchstone. ISBN 978-1-4165-7534-4.

LeJeune, P. 1994. El pacto autobiográfico y otros estudios. Madrid: Endymion. ISBN 9788488803030.

Levy, S. 2007. Amazon: Reinventing The Book. En: Newsweek. 17 Nov 2007. Disponible en: http://www.newsweek.com/amazonreinventing-book-96909

Mazzei, L.A. \& Jackson, A.Y. 2009. Voice in qualitative inquiry. Challenging conventional, interpretive, and critical conceptions in qualitative research. London: Routledge. ISBN 978-0415442213

Mirzoeff, N. 1999. An Introduction to Visual Culture. London: Routledge. ISBN 978-0-203-01413-4.

Milliot, J. \& Deahl, R. 2016. En: Publishers Weekly. 8 May 2015. Disponible en: [http://www.publishersweekly.com/pw/bytopic/industry-news/publisher-news/article/66593-amazon-publishing-marches-on.html .

Moen, E. 2009-2017. Sitios web personales. Disponibles en: http://www.erikamoen.com/; http://www.darcomic.com;

http://www.ohjoysextoy.com

Monge, Y. 2014. Lucha de titanes por el futuro del libro. En: El País. 2 Jun 2014. Disponible en: http://cultura.elpais.com/cultura/2014/06/02/actualidad/1401731563_075404.html

Norton, L.D. 2016. Amazon the Monopoly: Getting Smart About Books. En: The Huffington Post. 11 Feb 2017. Disponible en: http://www.huffingtonpost.com/lisa-dale-norton/amazon-the-monopoly-getti_b_9203680.html

Vauhini, V. 2015. Is Amazon Creating A Cultural Monopoly? En: The New Yorker. 23 Aug 2015. Disponible en:http://www.newyorker.com/business/currency/is-amazon-creating-a-cultural-monopoly

Verstappen, N. 2008. James Kochalka : American Elf. En: du9 I'autre bande dessinnée. Oct 2008. Disponible en:http://www.du9.org/en/entretien/james-kochalka-american-elf1048/

Wasserman, S. 2012. The Amazon Effect. Amazon got big fast, hastening the arrival of digital publishing. But how big is too big? En: The Nation. 29 May 2012. Disponible en: https://www.thenation.com/article/amazon-effect/

Whitlock, G. 2006. Autographics: The Seeing "I" of the Comics. MFS Modern Fiction Studies, 52(4), pp. 965-979. ISSN 1080-658X The Johns Hopkins University Press.

Wolff , J. 1998. La producción social del arte. Madrid: Istmo. ISBN 84-7090-346-2. 